\title{
The association between the serum level of vitamin $D$ and ischemic heart disease: a study from Jordan
}

This article was published in the following Dove Press journal: Vascular Health and Risk Management

\author{
Mohamad I Jarrah' \\ Nizar M Mhaidat ${ }^{2}$ \\ Karem H Alzoubi ${ }^{2}$ \\ Nasr Alrabadi ${ }^{3}$ \\ Enas Alsatari ${ }^{2}$ \\ Yousef Khader ${ }^{4}$ \\ Moath F Bataineh ${ }^{5}$
}

'Department of Internal Medicine, Faculty of Medicine, Jordan University of Science and Technology, Irbid, Jordan; ${ }^{2}$ Department of Clinical Pharmacy, Faculty of Pharmacy, Jordan University of Science and Technology, Irbid, Jordan; ${ }^{3}$ Department of Pharmacology, Faculty of Medicine, Jordan University of Science and Technology, Irbid, Jordan; ${ }^{4}$ Department of Public Health and Community Medicine, Faculty of Medicine, Jordan University of Science and Technology, Irbid, Jordan; ${ }^{5}$ Department of Sport Rehabilitation, Faculty of Physical Education and Sport Sciences, Hashemite University, Zarqa, Jordan

Correspondence: Mohammad I Jarrah Department of Internal Medicine, Faculty of Medicine, Jordan University of Science and Technology, PO Box 3030; Irbid

22110, Jordan

Tel +962 27201000 ext 2352

Fax +962 27201075

Email mijarrah@just.edu.jo

Nasr Alrabadi

Department of Pharmacology, Faculty of Medicine, Jordan University of Science and Technology, Irbid 221 I0, Jordan

Tel +96227201000 ext 23888

Email nnalrabadi@just.edu.jo
Background: Decreased levels of vitamin D were associated with increased risk of multiple diseases, including cardiovascular diseases. However, there seem to be some discrepancies among the results obtained from different studies. The aim of the present study was to explore the importance of having sufficient serum levels of vitamin D in reducing the incidence and the progression of coronary artery stenosis and ischemic heart disease (IHD).

Methods: Serum levels of vitamin D were measured using radioimmunoassay in 186 Jordanian patients who underwent investigative coronary catheterization. Of these patients, 133 were suffering from coronary artery stenosis. The association between vitamin D levels, coronary stenosis and many risk factors was determined using SPSS software.

Results and conclusions: Interestingly, the current results did not show an association between vitamin D abnormalities and the incidence or the reoccurrence of coronary artery stenosis. Moreover, significant differences were detected in the prevalence of vitamin D abnormalities based on the patient's gender, and there was a significant association between vitamin $\mathrm{D}$ abnormalities and both body mass index and dyslipidemia. However, current results did not show any significant association with other risk factors for IHD. For instance, no association was found with smoking, hypertension, diabetes mellitus, stable and unstable angina or with acute recent myocardial infarction.

Keywords: vitamin D, ischemic heart disease, IHD, coronary artery stenosis, cardiovascular system

\section{Introduction}

Vitamin D (25 hydroxyvitamin D (25[OH]D)) abnormality “either deficiency or insufficiency" is a common global epidemic condition, irrespective of geographical distribution, age, or ethnicity and despite the worldwide efforts against rickets. ${ }^{1}$ Vitamin D can affect the general population and can be detected in patients suffering from chronic diseases. ${ }^{2,3}$

The specific clinical manifestations of vitamin D deficiency/insufficiency might be seen as rickets in children, or alternatively, it can precipitate or exacerbate osteopenia, osteoporosis and bone fractures in adults. ${ }^{4}$ The etiology and pathogenesis may vary and are not always clearly understood. However, major causes of deficiency/insufficiency are related to inadequate food intake or inadequate exposure to sunlight., ${ }^{4,5}$

The steroidal structure of this vitamin and its ability to penetrate cellular barriers can predict for its critical role in regulating cellular function, proliferation and differentiation. ${ }^{3}$ Thereafter, the causal association between vitamin $\mathrm{D}$ abnormalities and the risk of developing or modulating many other diseases can be appreciated. For instance, 
vitamin D abnormalities were linked to the development of multiple arms of the metabolic syndrome. ${ }^{6}$ In agreement with that, increased levels of vitamin $\mathrm{D}$ were associated with better glycemic control in patients with type 2 diabetes mellitus (DM). ${ }^{7}$ As well, recent meta-analysis reviews suggested an indirect role of vitamin $\mathrm{D}$ in controlling blood pressure. ${ }^{89}$ Moreover, many studies suggested an integral role for the active form of vitamin D (calcitriol) in modulating inflammatory response. However, the clinical value of vitamin $\mathrm{D}$ in modulating inflammatory diseases is still controversial. ${ }^{10} \mathrm{Of}$ worthy to mention, the causal association between vitamin $\mathrm{D}$ abnormalities and different aspects of dyslipidemia, one of the major components of metabolic syndrome, still needs more investigation and validation. ${ }^{11}$

Previous studies have shown accumulating evidence on the association between vitamin $\mathrm{D}$ deficiency and increased incidence of cardiovascular diseases, such as, hypertension, ${ }^{9}$ left ventricular hypertrophy, ${ }^{12}$ heart failure, ${ }^{13}$ peripheral arterial disease $\mathrm{e}^{14}$ and myocardial infarction. ${ }^{15}$ These associations were further strengthened based on the significant association between vitamin $\mathrm{D}$ abnormalities and the presence of pathophysiological processes underlying atherosclerosis, for instance, inflammation, abnormal vascular function including increased arterial stiffness, abnormal vascular endothelial reactivity, decreased coronary blood flow and vascular calcification including uremic calcification. ${ }^{16-18}$ In addition, the causal association between vitamin $\mathrm{D}$ abnormalities and the previously mentioned metabolic diseases can further strengthen this notion. However, controversies do exist between studies conducted in different countries and under different clinical conditions.

The present study aimed at assessing the association between the serum levels of vitamin $\mathrm{D}$ and the incidence or reoccurrence of coronary artery restenosis following catheterization and stent implantation in Jordanian adult patients with ischemic heart disease (IHD). Current results could help defining a clinical paradigm for the prevention of atherosclerotic stenosis in patients with coronary artery disease.

\section{Patients and methods}

\section{Study population and design}

The study was a single-center, crossover, observational study that was conducted in tertiary health care level settings after receiving the proper approval from the institutional review board at King Abdullah University Hospital in Jordan. All participants in this study provided written informed consent. A total of 186 patients were subjected to the study between September 2014 and December 2015. Those patients were identified by having investigative/diagnostic catheterization for the exclusion of significant coronary artery disease (CAD) before non-coronary cardiac surgeries as a result of having an indication of developing IHD after thrombolysis in myocardial infarction (TIMI) score evaluation. This was done even if they had asymptomatic condition, suspected to have acute coronary syndrome, positive exercise stress test or contraindications to obtain exercise stress test, uninterpretable stress test results, suspected coronary anomalies or congenital heart disease. Concomitantly, those patients were further categorized under two different subgroups; the first group comprised 133 patients who were found to have significant artery stenosis and accordingly received a stent implantation (DESyne ${ }^{\circledR}$ Novolimustm-eluting coronary stent system, cobalt chromium platform, Elixir Medical Corporate, Milpitas, CA, USA). The second group comprised 53 age- and gender-matched subjects with normal (apparently healthy) coronary arteries, which was considered as the control group for the study. The exclusion criteria, for this study, included: severe valve disease, liver or kidney failure, diseases related to bone metabolism, primary or secondary hyperparathyroidism, use of drugs affecting calcium metabolism, history of malignancy or osteoporosis. Demographic and clinical properties were recorded, and blood samples were obtained for biochemical and vitamin $\mathrm{D}(25[\mathrm{OH}] \mathrm{D})$ analyses.

\section{Laboratory and biochemical measurements}

Blood samples were collected at the morning of the catheterization procedure and after overnight fasting. Levels of total cholesterol, high-density lipoprotein cholesterol and triglycerides in serum were measured using an Abbott Aeroset autoanalyzer with original kits (Abbott Laboratories, Abbott Park, IL, USA). Low-density lipoprotein cholesterol levels were calculated using Friedewald equation.

A radioimmunoassay procedure was used to measure vitamin D (25[OH] D) levels (DiaSorin, Stillwater, MN, USA). The intra- and inter-assay coefficients of variations (CVs) were $3 \%$ and $3.3 \%$, respectively. According to the serum levels of vitamin $\mathrm{D}$, patients were categorized into three subgroups; patients with vitamin D deficiency (vitamin D level of $<20 \mathrm{ng}$ / $\mathrm{mL}$ ), patients with vitamin D insufficiency (vitamin D level of 20-30 ng/mL) and patients with normal levels of vitamin D (vitamin D level of $>30 \mathrm{ng} / \mathrm{mL}$ ). High-sensitivity C-reactive protein level was determined by immuno-turbidimetric method (Abbott Aeroset 1600, Abbott reagents; Abbott Laboratories). Serum uric acid levels were measured using an enzymatic colorimetric test on a Roche Hitachi 911 Chemistry Analyzer (Hoffman-La Roche Ltd., Basel, Switzerland). 


\section{Statistical analysis}

Statistical analysis was performed using SPSS software (version 16.0; SPSS, Chicago, IL, USA). The associations between the categorical variables and vitamin $\mathrm{D}$ subcategories were tested using the chi-square test. Independent $t$-test was performed to compare the mean of vitamin $\mathrm{D}$ concentration between the categorical variables. Bivariate Pearson correlation was used to study the association of some continuous variables (age and body mass index [BMI]) with the concentration level of vitamin D. The associations or the differences were considered significant when $p$-value $<0.5$.

\section{Results}

The present study included 186 participants who were initially suspected to have IHD. Their sociodemographic and clinical characteristics were obtained. Alarmingly, most of our patients were not having normal/sufficient levels of vitamin D (94.1\%). Of the $94.1 \%$ of patients, $69.9 \%$ were suffering from vitamin D deficiency, whereas $24.2 \%$ were suffering from vitamin D insufficiency.

\section{Association between vitamin $\mathrm{D}$ levels and risk factors for IHD}

As expected, the number of male patients $(n=144)$ was higher than the number of female patients $(n=42)$, with $3: 1$ ratio. As well, the ratios for the number of patients who were suffering from vitamin $\mathrm{D}$ deficiency compared to the other groups (normal or insufficiency) were 2:1 and 4:1 for males and females, respectively. The percentage of patients with normal vitamin D levels was comparable between both genders ( $6.3 \%$ of male patients and $4.8 \%$ of female patients). Yet, the percentage of the patients who were suffering from vitamin D deficiency (compared to the percentage of patients who were suffering from insufficiency) was lower in male patients ( $66 \%$ vs $27.8 \%$, respectively) when compared to female patients ( $83.3 \%$ vs $11.9 \%$, respectively). In general, vitamin $\mathrm{D}$ levels were significantly lower in female patients when compared to males $(P=0.036)$ (Table 1).

The association between many atherosclerotic risk factors and vitamin D deficiency or insufficiency was obtained with focus on factors associated with metabolic syndrome (hypertension, DM and dyslipidemia) and smoking. Current findings showed that vitamin D levels were reversely associated with the coincidence of dyslipidemia, where patients who were not complaining of dyslipidemia appeared to suffer from high levels of vitamin $\mathrm{D}$ abnormality $(P=0.035)$. No correlation was found between the coincidence of smoking, hypertension or DM and vitamin D deficiency or insufficiency $(P=0.213,0.258$ and 0.73 , respectively).

Of interest, there was a significant reverse association between vitamin $\mathrm{D}$ concentration/ measurements and the value of the patient's BMI $(P=0.015)$. It appeared that patients with lower BMI can have higher levels of vitamin $\mathrm{D}$, regardless of being normal or abnormal levels.

\section{Association between vitamin $D$ levels and previous incidences of IHD}

No correlation was found between previous incidences of IHD and the subcategory of vitamin D abnormality. However, the number of patients with previous incidences of IHD was very low in the current study (Table 2).

\section{Association between vitamin D levels and the anatomical location of coronary artery stenosis}

According to this study, there was no association between vitamin $\mathrm{D}$ levels and the anatomical location of the coronary artery stenosis. Left anterior coronary artery, posterior coronary artery and left circumflex artery were the most affected arteries by coronary stenosis (Table 3 ).

\section{Association between vitamin $D$ levels and the incidence of coronary stenosis or restenosis despite supplementation}

Current results showed no correlation between the levels of vitamin D and the prevalence of coronary stenosis. As well, there was no association between vitamin D levels and the incidence of new coronary stenosis (restenosis) in the same patients after at least 2 years of follow-up, although there was a trend of significant association between vitamin $\mathrm{D}$ levels and the incidence of restenosis $(0.1>P$-value $>0.05)$. However, the small number of patients who came back for follow-up and who were found to suffer from coronary restenosis made us careful about this interpretation (Table 4).

\section{Discussion}

Vascular endothelial cells, smooth muscle cells and inflammatory cells can play complementary roles in vascular homeostasis and in the formation and stabilization of atherosclerotic legions. ${ }^{19-21}$ The presence of vitamin D receptors within the nucleus of these cells can advocate for its integral mechanistic role in the development and progression of ischemic diseases, ${ }^{15,22-24}$ especially due to the fact that the activation of these receptors has the ability to affect the 
Table I The association between vitamin D levels and risk factors for ischemic heart disease

\begin{tabular}{|c|c|c|c|c|}
\hline \multirow{2}{*}{$\begin{array}{l}\text { Categorical } \\
\text { variables }\end{array}$} & \multicolumn{3}{|c|}{ Association with vitamin $D$ levels according to vitamin $D$ subcategories } & \multirow{2}{*}{$\begin{array}{l}\text { Association with } \\
\text { vitamin D levels } \\
\text { according to vitamin D } \\
\text { concentration }\end{array}$} \\
\hline & $\begin{array}{l}\text { Deficiency, } \mathbf{n} \text { (\% within } \\
\text { vitamin D subcategory) }\end{array}$ & $\begin{array}{l}\text { Insufficiency, } \mathbf{n} \text { (\% within } \\
\text { vitamin D subcategory) }\end{array}$ & $\begin{array}{l}\text { Normal, } \mathbf{n} \text { (\% within } \\
\text { vitamin D subcategory) }\end{array}$ & \\
\hline Gender & \multicolumn{3}{|c|}{$P$-value: 0.086} & \multirow[t]{5}{*}{$\begin{array}{l}t \text {-test according to } \\
\text { categorical variables } \\
P \text {-value: } 0.036\end{array}$} \\
\hline \multirow[t]{2}{*}{ Female } & $35(26.9)$ & $5(I I . I)$ & $2(18.2)$ & \\
\hline & \multicolumn{3}{|c|}{ Percentages within females according to vitamin D subcategory (83.3\%, II.9\% and 4.8\%) } & \\
\hline \multirow[t]{2}{*}{ Male } & $95(73.1)$ & $40(88.9)$ & $9(81.8)$ & \\
\hline & \multicolumn{3}{|c|}{ Percentages within males according to vitamin D subcategory $(66 \%, 27.8 \%$ and $6.3 \%)$} & \\
\hline Smoking & \multicolumn{3}{|c|}{$P$-value: 0.213} & $\begin{array}{l}t \text {-test according to } \\
\text { categorical variables } \\
P \text {-value: } 0.249\end{array}$ \\
\hline \multirow[t]{2}{*}{ No } & $54(42.5)$ & $25(56.8)$ & $4(36.4)$ & \\
\hline & \multicolumn{3}{|c|}{ Percentages within non-smokers according to vitamin D subcategory $(65.1 \%, 30.1 \%$ and $4.8 \%)$} & \\
\hline \multirow[t]{2}{*}{ Yes } & $73(57.5)$ & $19(43.2)$ & $7(63.6)$ & \\
\hline & \multicolumn{3}{|c|}{ Percentages within smokers according to vitamin D subcategory $173.7 \%, 19.2 \%$ and $7.1 \%)$} & \\
\hline Hypertension & \multicolumn{3}{|c|}{$P$-value: 0.258} & $\begin{array}{l}t \text {-test according to } \\
\text { categorical variables } \\
P \text {-value: } 0.013\end{array}$ \\
\hline \multirow[t]{2}{*}{ No } & $53(40.8)$ & $22(48.9)$ & $7(63.6)$ & \\
\hline & \multicolumn{3}{|c|}{$\begin{array}{l}\text { Percentages within non-hypertensive patients according to vitamin D subcategory } \\
(64.6 \%, 26.8 \% \text { and } 8.5 \%)\end{array}$} & \\
\hline \multirow[t]{2}{*}{ Yes } & 77 (59.2) & 23 (5I.I) & $4(36.4)$ & \\
\hline & \multicolumn{3}{|c|}{$\begin{array}{l}\text { Percentages within hypertensive patients according to vitamin D subcategory } \\
(74 \%, 22.1 \% \text { and } 3.8 \%)\end{array}$} & \\
\hline Diabetes mellitus & \multicolumn{3}{|c|}{$P$-value: 0.730} & $\begin{array}{l}t \text {-test according to } \\
\text { categorical variables } \\
P \text {-value: } 0.114\end{array}$ \\
\hline \multirow[t]{2}{*}{ No } & $81(62.3)$ & $31(68.9)$ & $7(63.6)$ & \\
\hline & \multicolumn{3}{|c|}{$\begin{array}{l}\text { Percentages within non-diabetic patients according to vitamin D subcategory } \\
(68.1 \%, 26.1 \% \text { and } 5.9 \%)\end{array}$} & \\
\hline \multirow[t]{2}{*}{ Yes } & 49 (37.7) & $14(31.1)$ & $4(36.4)$ & \\
\hline & \multicolumn{3}{|c|}{$\begin{array}{l}\text { Percentages within diabetic patients according to vitamin D subcategory } \\
(73.1 \%, 20.9 \% \text { and } 6 \%)\end{array}$} & \\
\hline Dyslipidemia & \multicolumn{3}{|c|}{$P$-value: 0.035} & $\begin{array}{l}t \text {-test according to } \\
\text { categorical variables } \\
P \text {-value: } 0.125\end{array}$ \\
\hline \multirow[t]{2}{*}{ No } & $116(89.2)$ & $33(173.3)$ & $9(8 \mid .8)$ & \\
\hline & \multicolumn{3}{|c|}{$\begin{array}{l}\text { Percentages within non-dyslipidemia patients according to vitamin D subcategory } \\
(73.4 \%, 20.9 \% \text { and } 5.7 \%)\end{array}$} & \\
\hline \multirow[t]{2}{*}{ Yes } & $14(10.8)$ & $12(26.7)$ & $2(18.2)$ & \\
\hline & \multicolumn{3}{|c|}{$\begin{array}{l}\text { Percentages within dyslipidemia patients according to vitamin D subcategory } \\
(50 \%, 42.9 \% \text { and } 7.1 \%)\end{array}$} & \\
\hline $\begin{array}{l}\text { Body mass index } \\
\text { (BMI) }\end{array}$ & & & & \begin{tabular}{|l|} 
Bivariate Pearson \\
correlation \\
$P$-value: 0.015 (negative \\
association)
\end{tabular} \\
\hline Age (years) & & & & $\begin{array}{l}\text { Bivariate Pearson } \\
\text { correlation } \\
P \text {-value: } 0.25\end{array}$ \\
\hline
\end{tabular}

expression and function of more than 200 genes. ${ }^{15,25}$ The possible association between vitamin D levels and many ischemic risk factors can strengthen such a notion. ${ }^{3,6-8,25,26}$
However, similar to other studies, ${ }^{15,22,27}$ results of the current study did not show significant association between these abnormalities and the incidence or prevalence of IHD. 
Table 2 The association between vitamin $D$ levels and previous incidences of ischemic heart disease

\begin{tabular}{|c|c|c|c|}
\hline \multirow{2}{*}{$\begin{array}{l}\text { Categorical } \\
\text { variables }\end{array}$} & \multicolumn{3}{|c|}{ Association with vitamin $D$ levels according to vitamin $D$ subcategories } \\
\hline & $\begin{array}{l}\text { Deficiency, n (\% within } \\
\text { vitamin D subcategory) }\end{array}$ & $\begin{array}{l}\text { Insufficiency, n (\% within } \\
\text { vitamin D subcategory) }\end{array}$ & $\begin{array}{l}\text { Normal, n (\% within } \\
\text { vitamin D subcategory) }\end{array}$ \\
\hline Stable angina & \multicolumn{3}{|c|}{$P$-value: 0.415} \\
\hline \multirow[t]{2}{*}{ No } & $126(96.9)$ & $45(100.0)$ & II (I00.0) \\
\hline & \multicolumn{3}{|c|}{ Percentages within the variable according to vitamin $\mathrm{D}$ subcategory $(69.2 \%, 24.7 \%$ and $6 \%)$} \\
\hline \multirow[t]{2}{*}{ Yes } & $4(31)$ & $0(0)$ & $0(0)$ \\
\hline & \multicolumn{3}{|c|}{ Percentages according to vitamin D subcategory ( $100 \%, 0 \%$ and $0 \%)$} \\
\hline Unstable angina & \multicolumn{3}{|c|}{$P$-value: 0.812} \\
\hline \multirow[t]{2}{*}{ No } & $126(96.9)$ & $44(97.8)$ & II (I00.0) \\
\hline & \multicolumn{3}{|c|}{ Percentages according to vitamin D subcategory $(69.6 \%, 24.3 \%$ and $6.1 \%)$} \\
\hline \multirow[t]{2}{*}{ Yes } & $4(3.1)$ & I (2.2) & $0(0)$ \\
\hline & \multicolumn{3}{|c|}{ Percentages according to vitamin D subcategory $(80 \%, 20 \%$ and $0 \%)$} \\
\hline Acute MI & & $P$-value: 0.177 & \\
\hline \multirow[t]{2}{*}{ No } & $121(93.1)$ & $45(100.0)$ & $10(90.9)$ \\
\hline & \multicolumn{3}{|c|}{ Percentages according to vitamin D subcategory $(68.8 \%, 25.6 \%$ and $5.7 \%)$} \\
\hline \multirow[t]{2}{*}{ Yes } & $9(6.9)$ & $0(.0)$ & I ( $(9.1)$ \\
\hline & \multicolumn{3}{|c|}{ Percentages according to vitamin D subcategory ( $90 \%, 0 \%$ and $10 \%)$} \\
\hline Recent MI & & $P$-value: 0.219 & \\
\hline \multirow[t]{2}{*}{ No } & $125(96.9)$ & $45(100.0)$ & $10(90.9)$ \\
\hline & \multicolumn{3}{|c|}{ Percentages according to vitamin D subcategory $(69.4 \%, 25 \%$ and $5.6 \%)$} \\
\hline \multirow[t]{2}{*}{ Yes } & $4(3.1)$ & $0(0)$ & I ( $(9.1)$ \\
\hline & \multicolumn{3}{|c|}{ Percentages according to vitamin D subcategory ( $80 \%, 05$ and $10 \%)$} \\
\hline
\end{tabular}

Table 3 The association between vitamin D levels and the anatomical location of coronary artery stenosis

\begin{tabular}{|c|c|c|c|}
\hline \multirow[t]{2}{*}{ Categorical variables } & \multicolumn{3}{|c|}{ Association with vitamin D levels according to vitamin $D$ subcategories } \\
\hline & Deficiency, $\mathbf{n}$ & Insufficiency, n & Normal, $\mathbf{n}$ \\
\hline Left main coronary artery & \multicolumn{3}{|c|}{$P$-value: 0.160} \\
\hline No & 120 & 38 & II \\
\hline Yes & 10 & 7 & 0 \\
\hline Left anterior descending & \multicolumn{3}{|c|}{$P$-value: 0.946} \\
\hline No & 52 & 17 & 4 \\
\hline Yes & 78 & 28 & 7 \\
\hline Diagonal & \multicolumn{3}{|c|}{$P$-value: 0.680} \\
\hline No & 104 & 32 & 9 \\
\hline Yes & 25 & 13 & 2 \\
\hline Ramus intermediate & \multicolumn{3}{|c|}{$P$-value: 0.408} \\
\hline No & 120 & 44 & 10 \\
\hline Yes & 10 & 1 & I \\
\hline Left circumflex & \multicolumn{3}{|c|}{$P$-value: 0.974} \\
\hline No & 79 & 30 & 6 \\
\hline Yes & 52 & 15 & 5 \\
\hline Marginal branch & \multicolumn{3}{|c|}{$P$-value: 0.215} \\
\hline No & 103 & 31 & 11 \\
\hline Yes & 27 & 14 & 0 \\
\hline Right coronary & \multicolumn{3}{|c|}{$P$-value: 0.648} \\
\hline No & 64 & 19 & 6 \\
\hline Yes & 66 & 26 & 5 \\
\hline Right posterior descending & \multicolumn{3}{|c|}{$P$-value: 0.439} \\
\hline No & 126 & 42 & 11 \\
\hline Yes & 4 & 3 & 0 \\
\hline
\end{tabular}

Vitamin D abnormalities are very common and considered the leading cause of supplemental nutrition deficiencies worldwide, especially in elderly. ${ }^{22,28}$ Reduced exposure to sunlight, gastrointestinal abnormalities, reduced activities and low skin synthesis in elderly ${ }^{22}$ can greatly predispose for this condition. In Jordan, the prevalence of vitamin D abnormalities was very high in patients with metabolic syndrome, postpartum women, night shift workers, infants and 
Table 4 The association between vitamin $D$ levels and the incidence of coronary stenosis or restenosis despite supplementation

\begin{tabular}{|l|l|l|l|}
\hline \multirow{2}{*}{ Categorical variables } & \multicolumn{4}{|l|}{ Association with vitamin D levels according to vitamin D sub-categories } \\
\cline { 2 - 4 } & Deficiency, $\mathbf{n}$ & \multicolumn{1}{l|}{ Insufficiency, $\mathbf{n}$} & Normal, $\mathbf{n}$ \\
\hline Coronary stenosis & P-value: 0.334 & 9 & 3 \\
\hline No & 41 & 36 & 8 \\
\hline Yes & 89 & \multicolumn{4}{|l|}{} \\
\hline Coronary restenosis over 2 years & P-value: 0.079 & 43 & 8 \\
\hline No & 115 & 2 & 3 \\
\hline Yes & 15 & & \\
\hline
\end{tabular}

patients with certain diseases. ${ }^{29-32}$ In agreement with that, the current study showed that most patients were having abnormal levels of vitamin D.

Correlation between vitamin D abnormalities and patient's gender has been previously reported. ${ }^{33-35}$ In the current study, female gender was associated with more severe cases of vitamin D deficiency. Apart from the hormonal and genetic factors, this can be attributed to cultural issues where females in Arab countries are less exposed to sunlight, possibly because they are excessively covered with clothes "wearing Hijab" and many of them stay at home for longer periods in comparison to men. ${ }^{36}$

\section{The association between vitamin $D$ levels and the main parameters of the metabolic syndrome}

Factors related to the metabolic syndrome, ${ }^{6}$ such as hypertension, ${ }^{8,9} \mathrm{DM}^{7,26}$ and dyslipidemia, have been associated with vitamin D abnormalities. In Jordan, previous studies did not show clear associations between vitamin D levels and these factors. ${ }^{29,37}$ Current study showed that vitamin D abnormalities can be associated in a way or another with some of these risk factors.

As mentioned earlier, the association between vitamin $\mathrm{D}$ abnormalities and hypertension in normal or diabetic patients was previously reported. ${ }^{38}$ In addition, the supplementation of vitamin D products may have the ability to reduce the arterial blood pressure either in normal or diabetic patients. This modulating effect can be possibly attributed to the inhibition of the renin-angiotensin-aldosterone (RAAS) system. ${ }^{39}$ Moreover, arterial stiffness and vascular dysfunction are evident in patients with vitamin D abnormalities, which may predispose for elevated blood pressure and atherosclerosis and may benefit, at least theoretically, from vitamin D supplementation. ${ }^{40,41}$ However, all these lines of evidence are challenged by the fact that most of the studies, which used vitamin D supplementation to ameliorate vascular dysfunction and the associated hypertension, failed to achieve consistent modulation..$^{27,42,43}$ These contradictory results can be supported by current findings where no association between the subcategories of vitamin $\mathrm{D}$ abnormality and hypertension was detected. Current study was able to show a significant decrease in vitamin D levels in hypertensive compared to the normal patients. ${ }^{44-47}$

$\mathrm{DM}$, on the other hand, is another risk factor that can predispose for IHD. Vitamin D abnormalities are thought to be associated with DM by affecting the RAAS system, the calcium cellular concentration and the inflammatory repertoire surrounding the pancreatic cells. ${ }^{48,49}$ However, in patients with DM, meta-analysis reviews failed to provide consistent evidence on the ability of vitamin D supplementation to modulate the course or progression of prediabetic or diabetic conditions. ${ }^{49-51}$ Therefore, it was not surprising that we could not detect any association between vitamin D levels and the prevalence of DM in our study.

Interestingly, current findings showed that vitamin D levels were reversely associated with the coincidence of dyslipidemia, where patients with dyslipidemia appeared to have better vitamin D subcategorical levels (deficiency vs insufficiency). However, these patients did not have proper and sufficient levels of vitamin D. On the other hand, there was no significant difference between patients with or without dyslipidemia based on vitamin D concentration. These contradictory results can be attributed to the nature of the measured parameters and the statistical analyses that were used, even within the same study. The integral role of cholesterol as a precursor for vitamin D synthesis and the cholesterol integral role in vitamin $\mathrm{D}$ proper absorption ${ }^{52}$ may explain why vitamin $\mathrm{D}$ levels may be reduced but cannot be totally deficient in patients with high cholesterol levels (dyslipidemia). Actually, this relationship may explain, in part, why vitamin D deficiency may be of epiphenomenal nature and may not be associated with increased risk of IHD, as more 
cholesterol, which is a risk for IHD, can be accompanied with better vitamin $\mathrm{D}$ levels.

Finally, there was a significant reverse association between vitamin $\mathrm{D}$ concentration and the value of the patient's BMI. It appeared that patients with lower BMI can have higher levels of vitamin D, regardless of being normal, insufficient or deficient in vitamin D levels. Part of this reduction may be related to the excessive destruction/deposition of vitamin $\mathrm{D}$ in adipose tissue (in patients with high BMI), rather than the $\mathrm{BMI}$ increase that was caused by vitamin $\mathrm{D}$ abnormalities. ${ }^{53,54}$ On the other hand, the established association between BMI measurement and different parameters of metabolic syndrome can explain the contradictory results regarding the association between vitamin D levels and these parameters. Hence, reduction in vitamin D levels with increased BMI may give false-positive association between vitamin D abnormalities (reduced levels) and the risk for developing hypertension, DM or IHD.

\section{Vitamin D and the prevalence/incidence of IHD}

In the current study, the anatomical location of atherosclerotic lesions, which were affecting coronary vessels, was not significantly associated or corresponding with vitamin D subcategorical levels. Previous reports have indications on the ability of vitamin D deficiency to differentially affect the stiffness and functions of the arteries based on their diameter and structure. ${ }^{55-57}$ However, in the current study, legions at either large or small (bifurcations) coronary vessels were not significantly associated with the changes in vitamin D levels.

On the other hand, we could not find correlation between the prevalence of IHD and the subcategorical level of vitamin D neither retrospectively by obtaining history for patients at the time of the study nor prospectively by patients' follow-up to identify any case of recurrent IHD. Recent and, especially, interventional studies support the current findings. ${ }^{15,22,27,45}$ It is possible that many factors can affect the development or recurrence of IHD, such as vitamin D levels, which can act as a confounder, and it appears that it has less influence than other factors. Current studies and randomized large clinical studies that are conducted continue to reveal and clarify the association between vitamin D and cardiovascular diseases. ${ }^{58}$

\section{Conclusion}

We could not find a significant indication on the feasibility of using vitamin D levels or the presence of vitamin D deficiency or insufficiency as predictors for the possibility of developing or reoccurring of coronary artery diseases.
However, vitamin D abnormalities could be related to IHD or other conditions, which may directly or indirectly affect the progression or prognosis of these diseases; hence, detecting its level and keeping within the normal range is encouraged.

\section{Disclosure}

The authors report no conflicts of interest in this work.

\section{References}

1. Holick MF. The vitamin D deficiency pandemic: approaches for diagnosis, treatment and prevention. Rev Endocr Metab Disord. 2017;18(2):153-165.

2. Wasson LT, Shimbo D, Rubin MR, Shaffer JA, Schwartz JE, Davidson $\mathrm{KW}$. Is vitamin $\mathrm{D}$ deficiency a risk factor for ischemic heart disease in patients with established cardiovascular disease? 10-year follow-up of the Nova Scotia Health Survey. Int J Cardiol. 2011;148(3):387-389.

3. Wang H, Chen W, Li D, et al. Vitamin D and chronic diseases. Aging Dis. 2017;8(3):346-353.

4. Haimi M, Kremer R. Vitamin D deficiency/insufficiency from childhood to adulthood: insights from a sunny country. World J Clin Pediatr. 2017;6(1):1-9.

5. Goring H, Koshuchowa S. Vitamin D deficiency in Europeans today and in Viking settlers of Greenland. Biochemistry (Mosc). 2016;81(12):1492-1497.

6. Prasad P, Kochhar A. Interplay of vitamin D and metabolic syndrome: a review. Diabetes Metab Syndr. 2016;10(2):105-112.

7. Mirhosseini N, Vatanparast H, Mazidi M, Kimball SM. The effect of improved serum 25-hydroxyvitamin D status on glycemic control in diabetic patients: a meta-analysis. $J$ Clin Endocrinol Metab. 2017;102(9):3097-3110.

8. Jeong HY, Park KM, Lee MJ, Yang DH, Kim SH, Lee SY. Vitamin D and hypertension. Electrolyte Blood Press. 2017;15(1):1-11.

9. Mehta V, Agarwal S. Does vitamin D deficiency lead to hypertension? Cureus. 2017;9(2):e1038.

10. Colotta F, Jansson B, Bonelli F. Modulation of inflammatory and immune responses by vitamin D. J Autoimmun. 2017;85:78-97.

11. Zittermann A, Gummert JF, Borgermann J. The role of vitamin D in dyslipidemia and cardiovascular disease. Curr Pharm Des. 2011;17(9):933-942.

12. Panizo S, Barrio-Vazquez S, Naves-Diaz M, et al. Vitamin D receptor activation, left ventricular hypertrophy and myocardial fibrosis. Nephrol Dial Transplant. 2013;28(11):2735-2744.

13. Meredith AJ, McManus BM. Vitamin D in heart failure. J Card Fail. 2013;19(10):692-711.

14. Chua GT, Chan YC, Cheng SW. Vitamin D status and peripheral arterial disease: evidence so far. Vasc Health Risk Manag. 2011;7:671-675.

15. Huang J, Wang Z, Hu Z, Jiang W, Li B. Association between blood vitamin $\mathrm{D}$ and myocardial infarction: a meta-analysis including observational studies. Clin Chim Acta. 2017;471:270-275.

16. Bikle DD. Vitamin D and the skin: physiology and pathophysiology. Rev Endocr Metab Disord. 2012;13(1):3-19.

17. Gallieni M, Cozzolino M, Fallabrino G, Pasho S, Olivi L, Brancaccio D. Vitamin D: physiology and pathophysiology. Int J Artif Organs. 2009;32(2):87-94.

18. Hou YC, Liu WC, Zheng CM, Zheng JQ, Yen TH, Lu KC. Role of vitamin D in uremic vascular calcification. Biomed Res Int. 2017;2017:2803579.

19. Cichon N, Lach D, Dziedzic A, Bijak M, Saluk J. Procesy zapalne w aterogenezie. [The inflammatory processes in atherogenesis]. Polski merkuriusz lekarski: organ Polskiego Towarzystwa Lekarskiego. 2017;42(249):125-128. Polish. 
20. Chistiakov DA, Melnichenko AA, Myasoedova VA, Grechko AV, Orekhov AN. Mechanisms of foam cell formation in atherosclerosis. $J \mathrm{Mol}$ Med (Berl). 2017;95(11):1153-1165.

21. Wang D, Wang Z, Zhang L, Wang Y. Roles of cells from the arterial vessel wall in atherosclerosis. Mediators Inflamm. 2017;2017:8135934.

22. Milazzo V, De Metrio M, Cosentino N, Marenzi G, Tremoli E. Vitamin D and acute myocardial infarction. World J Cardiol. 2017;9(1):14-20.

23. Somjen D, Weisman Y, Kohen F, et al. 25-Hydroxyvitamin D3-1alphahydroxylase is expressed in human vascular smooth muscle cells and is upregulated by parathyroid hormone and estrogenic compounds. Circulation. 2005;111(13):1666-1671.

24. Rahman A, Hershey S, Ahmed S, Nibbelink K, Simpson RU. Heart extracellular matrix gene expression profile in the vitamin D receptor knockout mice. J Steroid Biochem Mol Biol. 2007;103(3-5):416-419.

25. Norman PE, Powell JT. Vitamin D and cardiovascular disease. Circ Res. 2014;114(2):379-393.

26. Poolsup N, Suksomboon N, Plordplong N. Effect of vitamin D supplementation on insulin resistance and glycaemic control in prediabetes: a systematic review and meta-analysis. Diabet Med. 2016;33(3):290-299.

27. Veloudi P, Jones G, Sharman JE. Effectiveness of vitamin D supplementation for cardiovascular health outcomes. Pulse. 2017;4(4):193-207.

28. Wimalawansa SJ, Razzaque DMS, Al-Daghri NM. Calcium and vitamin D in human health: hype or real? J Steroid Biochem Mol Biol. Epub 2017 Dec 16.

29. Alkhatatbeh MJ, Abdul-Razzak KK, Khasawneh LQ, Saadeh NA. High prevalence of vitamin $D$ deficiency and correlation of serum vitamin $D$ with cardiovascular risk in patients with metabolic syndrome. Metab Syndr Relate Disord. 2017;15(5):213-219.

30. Mohammad KI, Kassab M, Shaban I, Creedy DK, Gamble J. Postpartum evaluation of vitamin D among a sample of Jordanian women. J Obstet Gynaecol. 2017;37(2):200-204.

31. Alefishat E, Abu Farha R. Determinants of vitamin D status among Jordanian employees: focus on the night shift effect. Int J Occup Med Environ Health. 2016;29(5):859-870.

32. Kassab M, Shaban I, Mohammad K, Creedy DK. Prevalence of hypovitaminosis $\mathrm{D}$ among Jordanian healthy infants: a descriptive cross sectional study. J Pediatr Nurs. 2016;31(2):e119-125.

33. Aleksova A, Belfiore R, Carriere C, et al. Vitamin D deficiency in patients with acute myocardial infarction: an Italian single-center study. Int J Vitam Nutr Res. 2015;85(1-2):23-30.

34. Chirita-Emandi A, Socolov D, Haivas C, Calapis A, Gheorghiu C, Puiu M. Vitamin D status: a different story in the very young versus the very old Romanian patients. PLoS One. 2015;10(5):e0128010.

35. Niculescu DA, Capatina CAM, Dusceac R, Caragheorgheopol A, Ghemigian A, Poiana C. Seasonal variation of serum vitamin D levels in Romania. Arch Osteoporos. 2017;12(1):113.

36. Batieha A, Khader Y, Jaddou H, et al. Vitamin D status in Jordan: dress style and gender discrepancies. Ann Nutr Metab. 2011;58(1):10-18.

37. Yasein N, Shroukh W, Hijjawi R. Serum vitamin D and the metabolic syndrome among osteoporotic postmenopausal female patients of a family practice clinic in Jordan. Adv Clin Exp Med. 2015;24(2):245-250.

38. Dakshinamurti K. Vitamins and their derivatives in the prevention and treatment of metabolic syndrome diseases (diabetes). Can J Physiol Pharmacol. 2015;93(5):355-362.

39. Vaidya A, Sun B, Larson C, Forman JP, Williams JS. Vitamin D3 therapy corrects the tissue sensitivity to angiotensin ii akin to the action of a converting enzyme inhibitor in obese hypertensives: an interventional study. J Clin Endocrinol Metab. 2012;97(7):2456-2465.
40. Pirro M, Manfredelli MR, Helou RS, et al. Association of parathyroid hormone and 25-OH-vitamin D levels with arterial stiffness in postmenopausal women with vitamin D insufficiency. J Atheroscler Thromb. 2012;19(10):924-931.

41. Lee JI, Oh SJ, Ha WC, et al. Serum 25-hydroxyvitamin D concentration and arterial stiffness among type 2 diabetes. Diabetes Res Clin Pract. 2012;95(1):42-47.

42. Rodriguez AJ, Scott D, Srikanth V, Ebeling P. Effect of vitamin D supplementation on measures of arterial stiffness: a systematic review and meta-analysis of randomized controlled trials. Clin Endocrinol. 2016;84(5):645-657.

43. Stojanovic M, Radenkovic M. Vitamin D versus placebo in improvement of endothelial dysfunction: a meta-analysis of randomized clinical trials. Cardiovasc Ther. 2015;33(3):145-154.

44. Weber KT, Rosenberg EW, Sayre RM. Suberythemal ultraviolet exposure and reduction in blood pressure. Am J Med. 2004;117(4): 281-282.

45. Al Mheid I, Quyyumi AA. Vitamin D and cardiovascular disease: controversy unresolved. J Am Coll Cardiol. 2017;70(1):89-100.

46. Ergenekon E, Gucuyener K, Dursun H, et al. Nitric oxide production in newborns under phototherapy. Nitric Oxide. 2002;6(1):69-72.

47. Buyukafsar K, Levent A, Un I, Ark M, Arikan O, Ozveren E. Mediation of nitric oxide from photosensitive stores in the photorelaxation of the rabbit corpus cavernosum. Eur J Pharmacol. 2003;459(2-3): 263-267.

48. Gysemans CA, Cardozo AK, Callewaert H, et al. 1,25-Dihydroxyvitamin D3 modulates expression of chemokines and cytokines in pancreatic islets: implications for prevention of diabetes in nonobese diabetic mice. Endocrinology. 2005;146(4):1956-1964.

49. Santos RKF, Brandao-Lima PN, Tete R, Freire ARS, Pires LV. Vitamin D ratio and glycaemic control in individuals with type 2 diabetes mellitus: a systematic review. Diabetes Metab Res Rev. Epub 2017 Dec 21.

50. Seida JC, Mitri J, Colmers IN, et al. Clinical review: effect of vitamin D3 supplementation on improving glucose homeostasis and preventing diabetes: a systematic review and meta-analysis. $J$ Clin Endocrinol Metab. 2014;99(10):3551-3560.

51. Jamka M, Wozniewicz M, Jeszka J, Mardas M, Bogdanski P, StelmachMardas M. The effect of vitamin D supplementation on insulin and glucose metabolism in overweight and obese individuals: systematic review with meta-analysis. Sci Rep. 2015;5:16142.

52. Huff T, Jialal I. Physiology, cholesterol. In: StatPearls. Treasure Island, FL: StatPearls Publishing; 2017.

53. Wortsman J, Matsuoka LY, Chen TC, Lu Z, Holick MF. Decreased bioavailability of vitamin D in obesity. Am J Clin Nutr. 2000;72(3):690-693.

54. Borel P, Caillaud D, Cano NJ. Vitamin D bioavailability: state of the art. Crit Rev Food Sci Nutr. 2015;55(9):1193-1205.

55. Manouchehri N, Vakil-Asadollahi M, Zandifar A, Rasmani F, Saadatnia M. Vitamin D status in small vessel and large vessel ischemic stroke patients: a case-control study. Adv Biomed Res. 2017;6:146.

56. Brooks AR, Lelkes PI, Rubanyi GM. Gene expression profiling of vascular endothelial cells exposed to fluid mechanical forces: relevance for focal susceptibility to atherosclerosis. Endothelium. 2004;11(1): $45-57$.

57. Chiu JJ, Usami S, Chien S. Vascular endothelial responses to altered shear stress: pathologic implications for atherosclerosis. Ann Med. 2009;41(1):19-28.

58. Pradhan AD, Manson JE. Update on the vitamin D and omega-3 trial (VITAL). J Steroid Biochem Mol Biol. 2016;155(Pt B):252-256. 
Vascular Health and Risk Management is an international, peerreviewed journal of therapeutics and risk management, focusing on concise rapid reporting of clinical studies on the processes involved in the maintenance of vascular health; the monitoring, prevention and treatment of vascular disease and its sequelae; and the involvement of metabolic disorders, particularly diabetes. This journal is indexed on PubMed Central and MedLine. The manuscript management system is completely online and includes a very quick and fair peer-review system, which is all easy to use. Visit http://www.dovepress.com/ testimonials.php to read real quotes from published authors. 